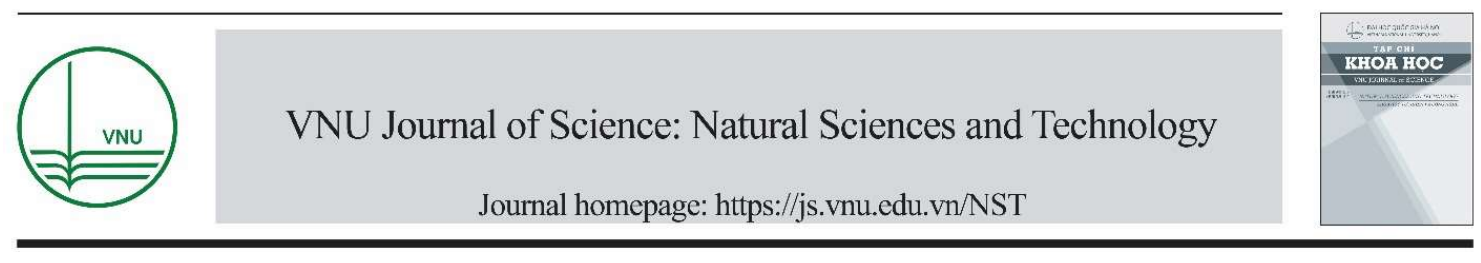

Original Article

\title{
Isolation and Selection of Purple Non-Sulfur Bacteria for Nutrient Rich Biomass Production from Wastes
}

\author{
Do Binh Minh, Pham The Hai* \\ VNU University of Science, 334 Nguyen Trai, Thanh Xuan, Hanoi, Vietnam
}

Received 28 August 2020

Revised 27 November 2020; Accepted 24 June 2021

\begin{abstract}
Purple nonsulfur bacteria (PNSB) are anoxygenic photosynthetic bacteria, which are able to photoheterotrophically grow in the presence of excessive nutrients. Hence, PNSB can convert organic components, in waste waters into nutrient rich biomass. This suggests the feasibility of converting wastes into valuable products. In this research, method for isolation of PNSB was optimized, and subsequently used for the isolation of PNSB from domestic waste and pond water samples taken in Hanoi. In addition, the effects of carbon and nitrogen sources and types of waste on biomass and nutrients (protein and carotenes) were also investigated. Four PNSB strains were isolated and based on comparative 16S rDNA analysis and their morphological characteristics, they were identified as Rhodobacter (Rb.) capsulatus, Rhodobacter (Rb.) sphaeroides, Rhodobacter (Rb.) sediminis and Rhodopseudomonas (Rp.) palustris. In terms of the effects of carbon and nitrogen sources on their biomass and nutrient production, glucose or maltose and ammonium chloride or urea were found to be more enhancive than starch and peptone, respectively. Among the studied strains, Rb. capsulatus MD1 and $R b$. sphaeroides MD3 showed significantly higher biomass production (up to $0.7 \mathrm{~g} / \mathrm{l}$ ) when growing with various carbon and nitrogen sources, in comparison with the other strains. Moreover, MD1 and MD3 also produced at least four-fold more carotenoid and up to two-fold more protein in tofu processing wastewater compared with the other wastewater. The results suggest potential applications of the PNSB strains for efficient conversions of organic compounds in wastes into biomass of high nutritional values.
\end{abstract}

Keyword: Purple Nonsulfur Bacteria, Biomass, Carotenoid, Protein, Waste-to-Nutrient Conversion

\footnotetext{
* Corresponding author.

Email address: phamthehai@vnu.edu.vn
}

https://doi.org/10.25073/2588-1140/vnunst.5121 


\section{Introduction}

Nowadays, through the development of industrialization and human daily activities, environmental pollution has dramatically increased. Therefore, the demand for waste treatment and waste management has also drastically increased. In response to this, there have been numerous studies on various methods to tackle waste from agriculture, aquaculture and food processing. Depending on the type of waste, those methods can involve physical treatments (grit chamber, flotation or equalization basin), chemical treatments (neutralization, oxidation or ion exchange) and biological treatments [1-4].

Unlike industrial waste, agriculture waste contains a higher organic content including protein, carbohydrate and fatty acids, due to its origin from plants and animals. Therefore, there is a current trend of research on how to recycle this potential waste for sustainability reasons. For this theme, technologies based on the use of purple nonsulfur bacteria (PNSB) appear very promising.

PNSB are photosynthetic Gram-negative prokaryotes that convert light into chemical energy by the process of anoxygenic photosynthesis. These bacteria contain photosynthetic pigments which are bacteriochlorophyll and carotenoids, and can grow best under photoheterotrophic conditions [5]. Apparently, carbon source and nitrogen source are necessary for the growth and the production of metabolites by microorganisms as they are important in microbial metabolism. Regarding PNSB, they can use a variety of carbon source and nitrogen source for their growth. They have flexible metabolism to use these sources in different habitats. Noticeably, it was reported that the four-carbon carboxylic acid carbon sources such as malate, succinate, etc. and the nitrogen sources containing the amino group help PNSB grow better and produce more pigments under anaerobic condition $[5,6]$.
PNSB can be isolated from various environments, including freshwater, marine systems or soils. These bacteria have been reported as efficient biological agents for use in wastewater treatment due to their diversity in metabolic activities and their production of nutrient products such as protein, vitamin and biohydrogen [7]. Moreover, the high nutritional value of their biomass makes them even attractive candidates for resource recovery from waste [8-11]. Particularly, their biomass produced from waste can be included in feed to promote growth, feed conversion ratio and survival of reared fish or used as a single cell protein source $[12,13]$. Due to those attractive potentials, there has been recently a great interest in searching for novel PNSB for efficient conversion of waste to biomass and in improving such conversion. Therefore, this study was conducted to find novel PNSB originating from domestic waste and pond samples in Hanoi and to investigate how key nutrients, including carbon sources and nitrogen sources, may affect the productions of biomass, total carotenoid and total protein of those PNSB. Based on these results, we preliminarily examined the waste-to-biomass conversion of the strains when growing on some common agriculture and food processing wastes in Vietnam.

\section{Materials and Methods}

\subsection{Waste Samples Collection}

Waste samples for the isolation of PNSB were collected from domestic wastewater sewers (Trieu Khuc, Hoang Cau, Kieu Mai) and some ponds (Thanh Cong, Dinh Cong) in Hanoi. For the experiment testing the waste-tobiomass conversion of the PNSB strains, we used several wastewater samples, including a brewery wastewater, a livestock wastewater and a tofu wastewater collected in Hanoi Beer Alcohol and Beverage Joint Stock Corporation (Van Lam, Hung Yen), in Sharefarm (PhucTho, Hanoi) and in a tofu-producing factory in Gia Lam, Hanoi, respectively. 


\subsection{Culture Enrichment and Isolation}

The isolation of PNSB from each waste sample was accomplished by adding that waste sample (the inoculum) to a liquid enrichment medium in a bottle or a falcon tube. Thus, the final volume contained the inoculum $(5-25 \%$ $(\mathrm{v} / \mathrm{v})$ and the enrichment medium filled up such that no air bubbles were trapped. The enrichment bottles were placed under yellow light (generated from a $15 \mathrm{~W}$ tungsten bulb producing an illuminance of ca. $7162 \mathrm{~lx}$ ) at temparatures ranging from $30-35^{\circ} \mathrm{C}$. Once the enrichment was achieved, which was indicated by the turbidity of the enrichment culture, the suspension was then plated with the enrichment medium before incubated anaerobically under the same condition.

The enrichment medium (SA medium) contained the following (per liter): KH2PO4, $0.33 \mathrm{~g}$; $\mathrm{MgSO} 4.7 \mathrm{H} 2 \mathrm{O}, 0.33 \mathrm{~g} ; \mathrm{NaCl}, 0.33 \mathrm{~g}$; $\mathrm{NH} 4 \mathrm{Cl}, 0.5 \mathrm{~g}$; $\mathrm{CaCl} 2,0.0377 \mathrm{~g}$; $(\mathrm{CH} 2 \mathrm{COOH}) 2$, $1 \mathrm{~g}$; yeast extract, $0.02 \mathrm{~g}$; trace elements, $1 \mathrm{ml}$; and distilled water filled up to the total volume. The final $\mathrm{pH}$ was adjusted to 7 and the medium sterillized by autoclaving.

\subsection{Bacterial Strain Identification by Morphological Characterization}

All isolates were characterized in terms of their morphology, utilization of different carbon sources. Gram staining was performed by the Coico method [14]. Motility was determined on semi-solid SA medium (containing $0.4 \%$ agar). For the carbon source experiment, succinateomitted SA medium was supplemented individually with glucose, acetate or citrate, while the experimental conditions were the same.

\subsection{Bacterial Strain Identification by $16 S$ rDNA Gene Sequences}

After doing morphological characterization, all isolates were characterized by $16 \mathrm{~S}$ rDNA gene sequences. $16 \mathrm{~S}$ ribosomal RNA gene fragments of the strains were amplified by PCR using forward primer $63 \mathrm{~F}$ (5'-CAG GCC TAA
CAC ATG CAA GTC-3') and reverse primer 1387R (5'-GGG CGG WGT GTA CAA GGC$\left.3^{\prime}\right)$. The PCR products were sequenced by IDT (First Base, Singapore), before they were analyzed by using "nucleotide-nucleotide BLAST" tool of National Center for Biotechnology Information.

\subsection{Study on the Effects of Carbon Sources on The Growth of PNSB}

For comparing and analyzing the effect of carbon sources for the growth of PNSB, we replaced succinate in the enrichment medium (SA) with glucose, maltose or starch while the total amount of carbon was kept the same at 500 $\mathrm{mgC} / \mathrm{ml}$. The effects of these media were subsequently examined by comparing the biomass weights, and the amounts of carotenoid and total protein produced by the strains grown on them.

\subsection{Study on the Effects of Nitrogen Sources on the Growth of PNSB}

For comparing and analyzing the effect of nitrogen sources for the growth of PNSB, $\mathrm{NH}_{4} \mathrm{Cl}$ in medium SA was replaced with urea or peptone while the total amount of nitrogen was kept the same at $500 \mathrm{mgN} / \mathrm{ml}$. The effects of these media were subsequently examined by comparing the biomass, and the amounts of carotenoid and total protein produced by the strains grown on them.

Evaluating the growths and protein and carotenoid production of PNSB in different types of wastewater based on the results of above experiments, we chose a brewery wastewater, a livestock wastewater and a tofu wastewater (mentioned in section 2.1), which respectively contain maltose, urea or starch and peptone as primary components. Before using for experiments, the $\mathrm{pHs}$ and CODs of the wastewater were adjusted to the same values ( $\mathrm{pH}$ to 7 by adding $\mathrm{NaOH}$ or $\mathrm{HCl}$ and $\mathrm{COD}$ to $800-1000 \mathrm{mg} / \mathrm{l}$ by dilution). Then the wastewater was used as the media for growing the strains and their productions of biomass, 
carotenoid and protein during the same growth period in the media compared.

\subsection{Growth and Protein and Carotenoid Contents Measurements}

The growth parameters in terms of dry cell weight $(\mathrm{g} / \mathrm{l})$, total carotenoid amount $(\mathrm{mg} / \mathrm{g}$ dry cell weight) and total protein amount $(\mu \mathrm{g} / \mathrm{ml})$ were monitored every day from all experiments.

In brief, to determine the dry cell weight, 35 $\mathrm{ml}$ of the culture of interest was centrifuged at $5000 \mathrm{rpm}, 4^{\circ} \mathrm{C}$ for 20 minutes. The pelleted cell mass was re-suspended again with distilled water and then centrifuged again under the same condition for washing. Finally, biomass was dried in oven at $105^{\circ} \mathrm{C}$ for $6 \mathrm{~h}$ [15].

Total carotenoid amount of PNSB cells were determined through acetone-methanol extraction. The ratio of acetone to methanol in the extraction mixture was 7:2 (v/v). Each liquid culture of interest was extracted with that mixture as described by Cohen-Bazire et al [16] and the 480-nm-wavelength light absorbance of the extract was measured .

Protein in each liquid culture of interest was solubilized by adding $1 \mathrm{ml}$ of $2 \mathrm{~N} \mathrm{NaOH}$ and $0.5 \mathrm{ml}$ distilled water to $1 \mathrm{ml}$ of the culture suspension and boiling for 5 minutes. After centrifugation at $5000 \mathrm{rpm}, 4^{\circ} \mathrm{C}$ for 20 minutes, the total protein concentration was determined by the dye binding method described by Bradford [17], based on a standard curve previously generated from measuring BSA standard solutions.

\subsection{Data Analysis}

Data analysis was carried out by using standard statistical tools of Microsoft Excel. The data were the results of the aforementioned experiments, which were repeated three times unless otherwise stated.

\section{Results and Discussion}

3.1. Isolation and Identification of PNSB
In this study, we tried different conditions for the enrichment and isolation of PNSB and found that a 4-day incubation under yellow light and at temperatures around $30-35^{\circ} \mathrm{C}$ on SA agar was more efficient than a 7-day incubation under white light and at room temperature (data not shown). Thus, by applying the former, we obtained 9 PNSB isolates, numbered from 1-9.

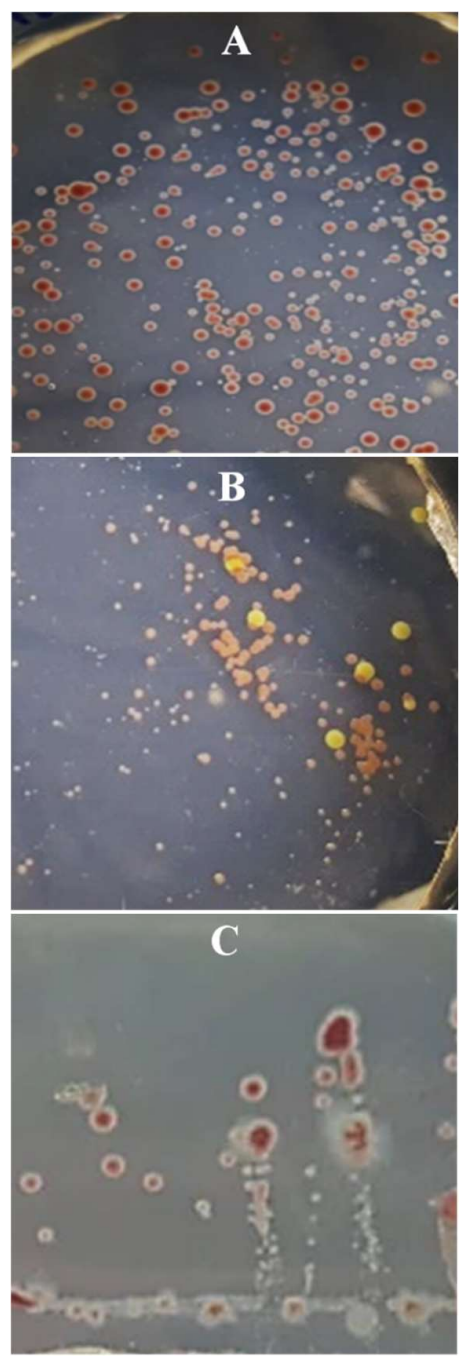

Figure 1. Colony morphology of the PNSB isolates in this study. Note: A: typical colonies of isolates 2 and 4; B: typical colonies of isolates 3,8,9; $\mathrm{C}$ : typical colonies of isolates $1,5,6,7$ 
By morphological observations, the PNSB cells were rod-shaped and their cell lengths were around $0.5-0.8 \mu \mathrm{m}$. All of the isolates were Gram-negative and motile. On SA agar, the color of the colonies of isolates 2 and 4 was red, whereas that of isolates $3,8,9$ was redorange and that of the others was reddish brown (Fig. 1).

These isolates were grown on SA medium (with succinate omitted) anaerobically under the yellow light and with different organic compounds as the main substrates. All of the isolates photo assimilated glucose while citrate was not utilized by them. Furthermore, only three isolates $(2,3,4)$ demonstrated their capability of using acetate as the sole substrate. Some characteristic features of the isolates, including their photoheterotrophic growth on different organic substrates, were summarized in Table 1.

Table 1. Physiological Characteristics of the PNSB isolates.

\begin{tabular}{ccccc}
\hline $\begin{array}{c}\text { Isolate } \\
\text { No. }\end{array}$ & Motility & $\begin{array}{c}\text { Glucose } \\
\text { utilized }\end{array}$ & $\begin{array}{c}\text { Acetate } \\
\text { utilized }\end{array}$ & $\begin{array}{c}\text { Citrate } \\
\text { utilized }\end{array}$ \\
\hline 1 & + & + & - & - \\
2 & + & + & + & - \\
3 & + & + & + & - \\
4 & + & + & + & - \\
5 & + & + & - & - \\
6 & + & + & - & - \\
7 & + & + & - & - \\
8 & + & + & - & - \\
9 & + & + & - & - \\
\hline
\end{tabular}

The 16S rDNA gene fragments of the 9 PNSB isolates were successfully amplified (data not shown). After sequencing, sequence analyses showed a $99 \%$ similarity of their gene fragment sequences to the respective sequences of typical PNSB: those of 4 isolates $(1,5,6$ and 7) to that of $R b$. capsulatus, those of 2 isolates $(2,4)$ to that of $R p$. palustris, that of isolate 3 to that of Rb. sphaeroides; and those of the last two isolates $(8,9)$ to that of $R b$. sediminis.

Analyzing the features of the 9 isolates shown in Table 1 by using the Bergey Manual and also their 16S rRNA gene sequences, we identified them to be 4 PNSB strains, designated as $R b$. capsulatus MD1 (isolates 1,5,6 and 7), Rp. palustris MD2 (isolates 2 and 4), $R b$. sphaeroides MD3 (isolate 3) and $R b$. sediminis MD4 (isolates 8 and 9).

\subsection{The Effect of Different Carbon Sources on the Growth of the PNSB Strains}

The dry cell weight of each of the 4 PNSB strains ( $R b$. capsulatus MD1, Rp. palustris MD2, $R b$. sphaeroides MD3 and Rb. sediminis MD4) was measured after 5 days of culture and the mean value recorded. All the strains produced more biomass when grown on SA medium containing glucose or maltose as the carbon source than when grown on the medium containing starch. Furthermore, Rb. capsulatus MD1 and $R b$. sphaeroides MD3 grew better than the others (Fig. 2).

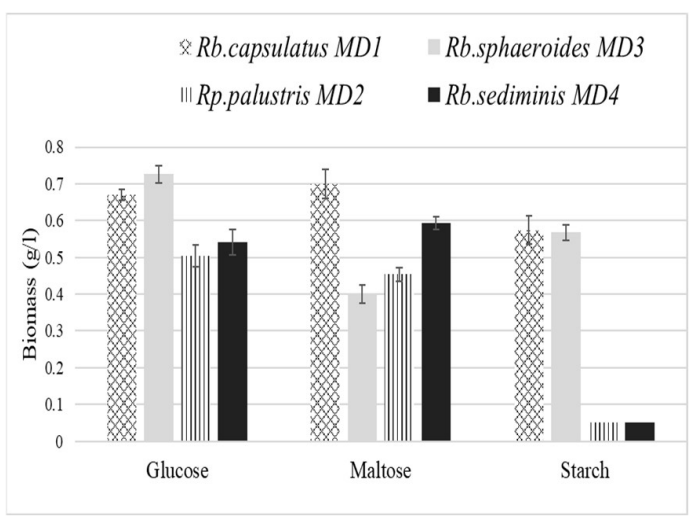

Figure 2. Biomass production of the 4 PNSB strains in different carbon sources. Note: The measurements were done after 5 days of incubation under same conditions (anaerobic incubation under yellow light and at temperature between $30-35^{\circ} \mathrm{C}$ ).

Similarly, the total carotenoid productions of the 4 PNSB strains were higher when they grew with glucose or maltose as carbon source. $R b$. capsulatus MD1 and Rb. sphaeroides MD3 also produced more carotenoid than $R p$. palustris MD2 and Rb. sediminis MD4 (Fig. 3). 


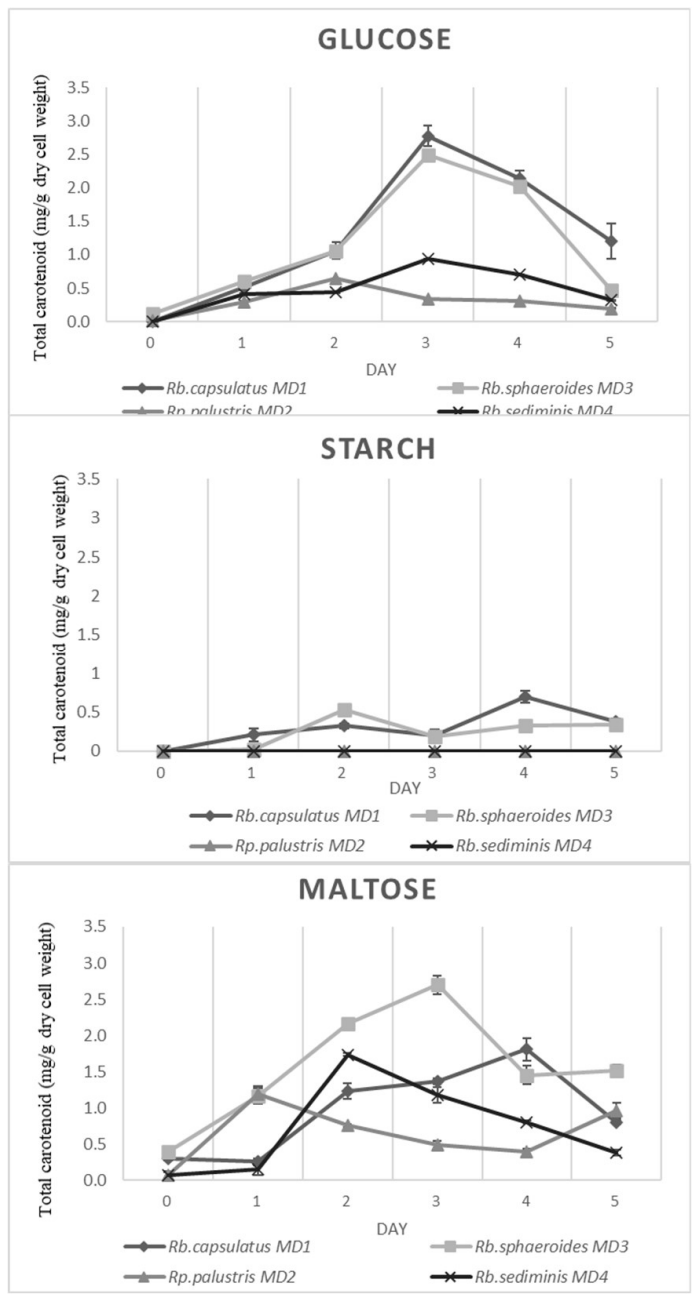

Figure 2. Carotenoid production of the 4 PNSB strains when growing in various carbon sources. Notes: The measurements with all samples were done after 5 days of culture under same conditions (anaerobic incubation under yellow light and at temperatures around $30-35^{\circ} \mathrm{C}$ ).

Regarding protein production, $R b$. capsulatus MD1 and Rb. sphaeroides MD3 produced remarkably higher protein amounts than Rp. palustris MD2 and Rb. sediminis MD4, when growing with all three carbon sources (Fig. 4). The results demonstrate that waste types containing sugars such as glucose and maltose are more suitable for the growth of PNSB and particularly the strains $\mathrm{Rb}$. capsulatus MD1 and Rb. sphaeroides MD3 in this study. These results are also similar to those of previous studies on the growths of $\mathrm{Rb}$. capsulatus and $\mathrm{Rb}$. sphaeroides on the organic compounds of some food industrial wastes such as soy sauce.

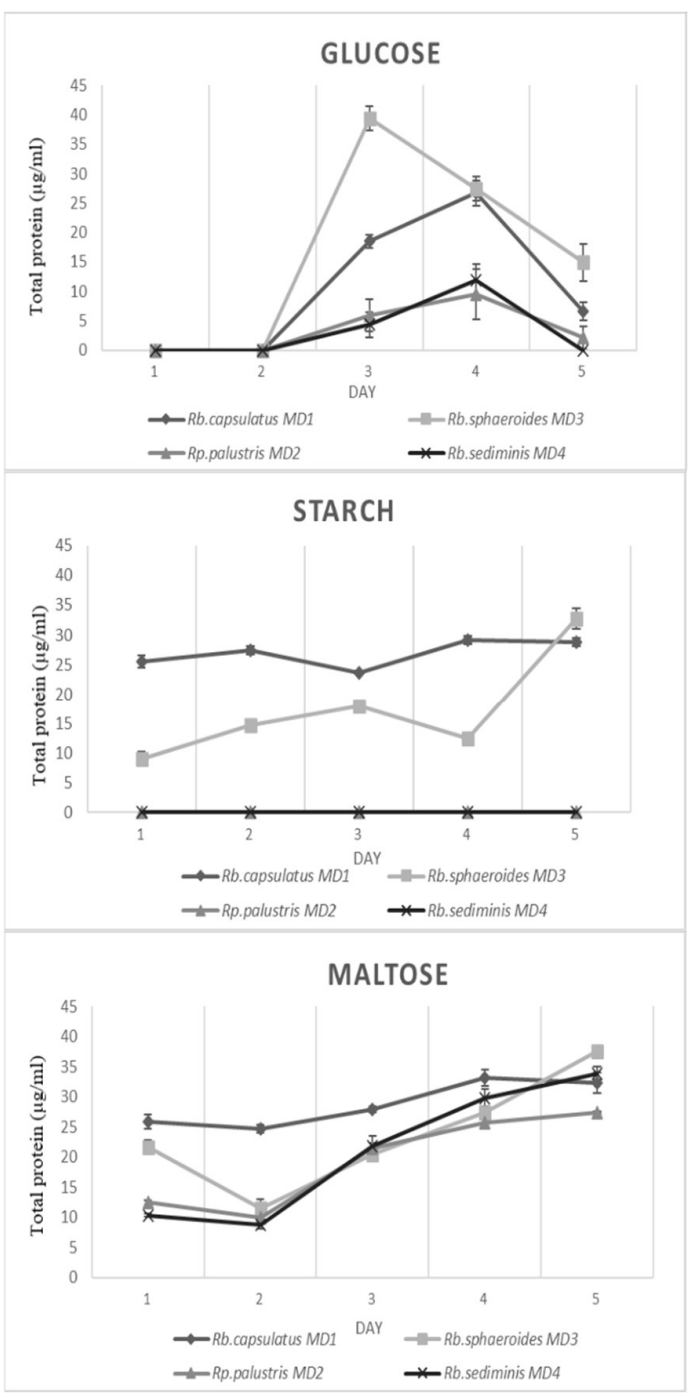

Figure 3. Protein productions of the 4 PNSB strains when growing with various carbon sources. Notes: The measurements with all samples were done after 5 days of culture under same conditions (anaerobic incubation under yellow light and at temperatures around $30-35^{\circ} \mathrm{C}$ ). 


\subsection{The Effect of Different Nitrogen} Sources on the Growth of PNSB

When the nitrogen source was altered, $R b$. capsulatus MD1 and Rb. sphaeroides MD3 produced higher dry biomass weight than the two other strains. That production is especially higher when the strains grew on the medium containing ammonium chloride or urea (Fig. 5).

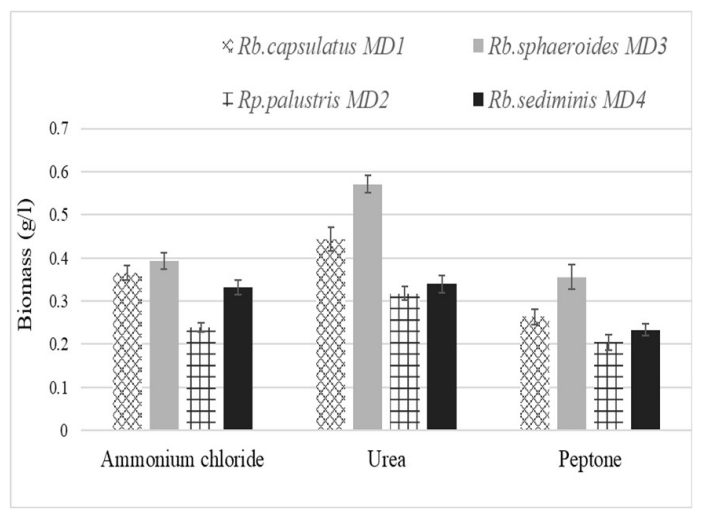

Figure 5. Biomass of 4 PNSB strains with different nitrogen sources. Note: The measurements with all samples were done after 5 days of culture under same conditions (anaerobic incubation under yellow light and at temperatures around $30-35^{\circ} \mathrm{C}$ ).

Total carotenoid and total protein measurement results indicated that SA medium containing ammonium chloride or urea also supported $R b$. capsulatus MD1 and $R b$. sphaeroides MD3 to produce more carotenoid and protein than the medium containing peptone (Fig. 6 and Fig. 7).

The results of nitrogen source experiment have illustrated that peptone is not an appropriate nitrogen source for $R b$. capsulatus MD1, Rp. palustris MD2, Rb. sphaeroides MD3 and $R b$. sediminis MD4 to produce carotenoid and protein. The reason may be the components of peptone, which include a complex mixture of polypeptides and amino acids that are difficult for these PNSB to metabolize. Some previous studies showed that only a few types of amino acids were suitable for the growth of PNSB [21, 22].

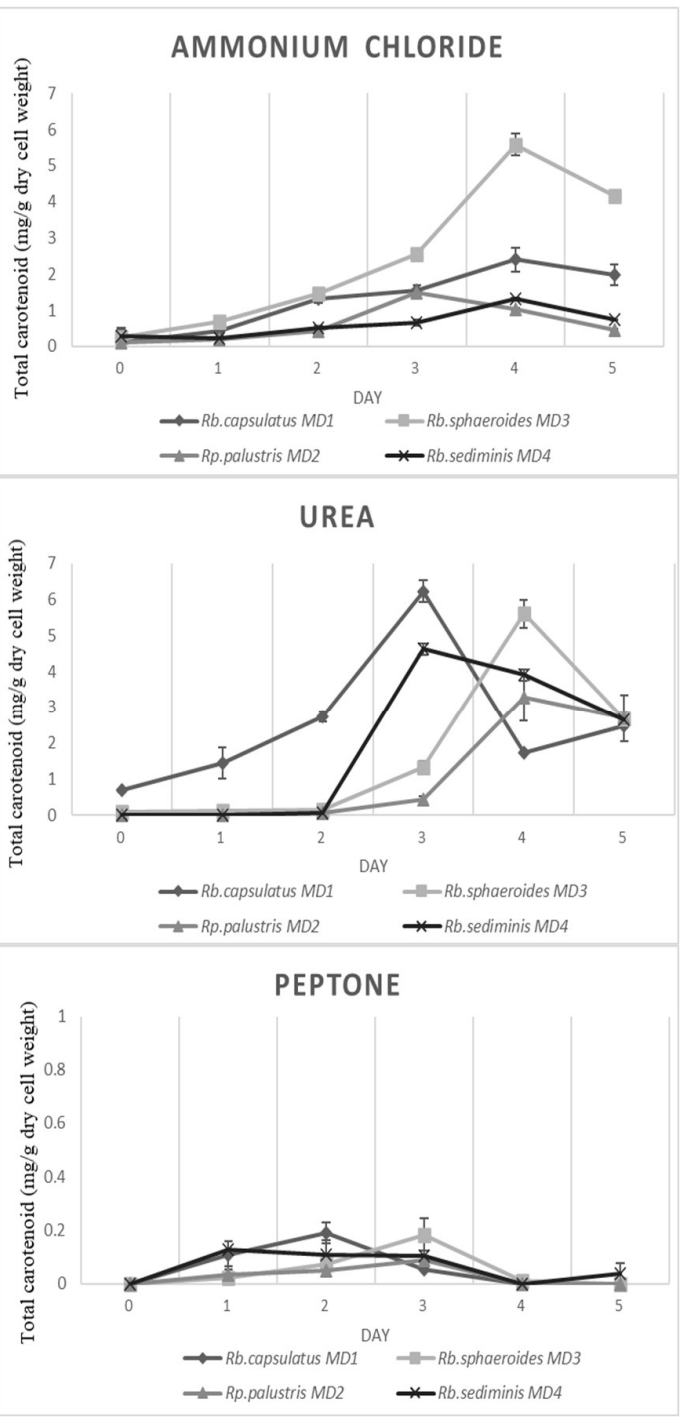

Figure 4. Production of total carotenoid (mg/g dry cell weight) in various nitrogen sources of 4 PNSB strains. Note: The measurements with all samples were done after 5 days of culture under same conditions (anaerobic incubation under yellow light and at temperatures around $30-35^{\circ} \mathrm{C}$ ). 

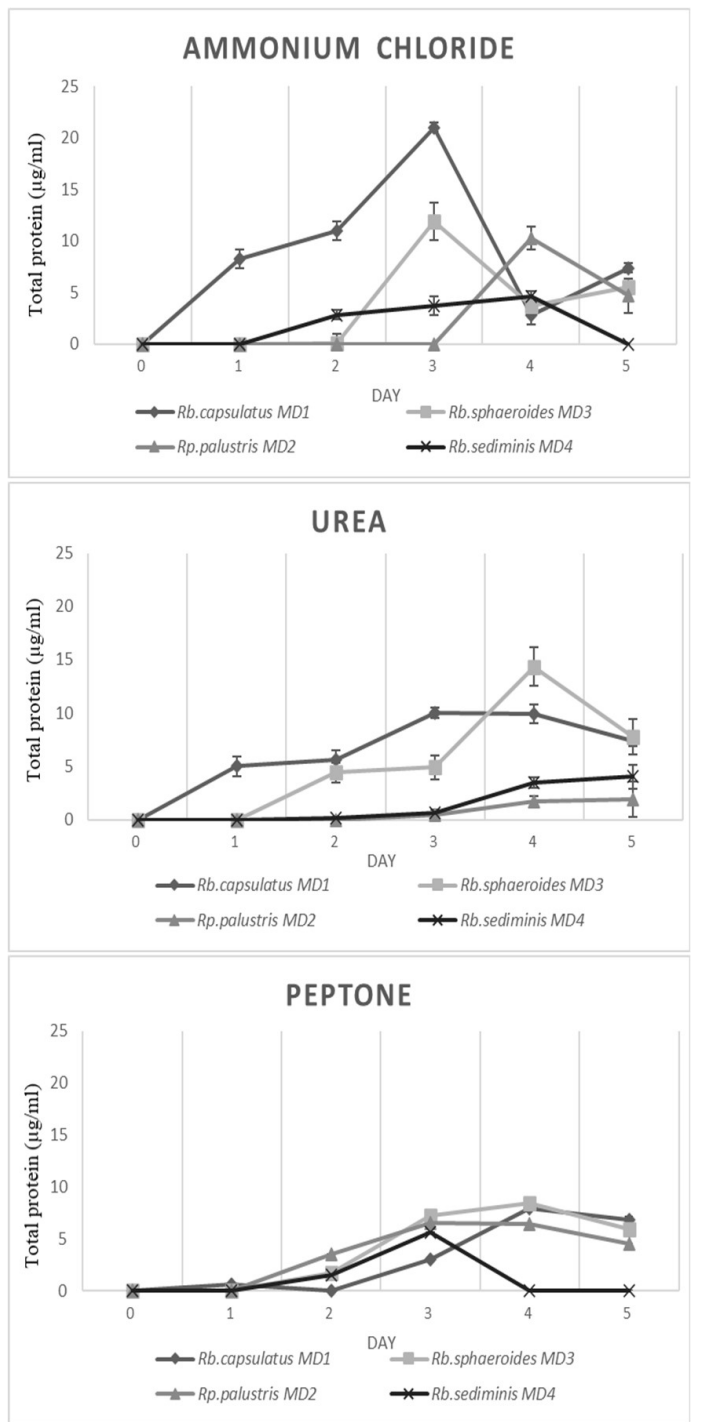

Figure 5. Production of total protein $(\mu \mathrm{g} / \mathrm{ml})$ in various nitrogen sources of 4 PNSB strains. Note: The measurements with all samples were done after 5 days of culture under same conditions (anaerobic incubation under yellow light and at temperatures around $30-35^{\circ} \mathrm{C}$ ).

\subsection{Production of Carotenoid and Protein} by the PNSB Strains When Growing on Real Wastewater - the Realistic Potential of Wasteto-biomass Conversion
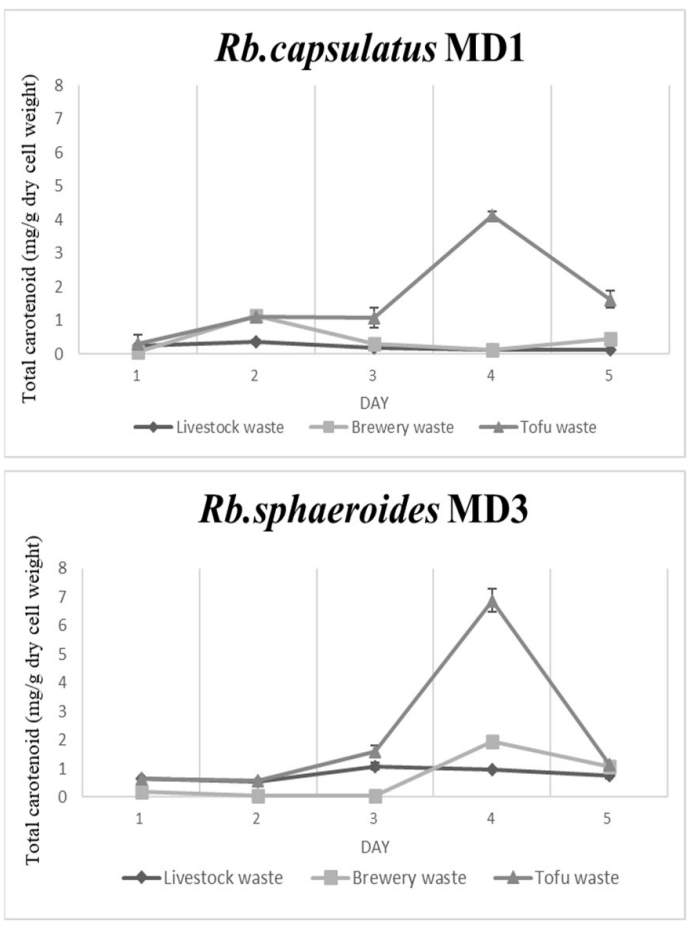

Figure 6. Carotenoid production patterns of $R b$. capsulatus MD1 and $R b$. sphaeroides MD3 when growing on various wastewater. Note: The measurements with all samples were done after 5 days of culture under same conditions (anaerobic incubation under yellow light and at temperatures around $30-35^{\circ} \mathrm{C}$ ).

The results of carbon source and nitrogen source experiments showed that the two strains $R b$. capsulatus MD1 and $R b$. sphaeroides MD3 were superior to the others and thus their wasteto-nutrients conversion potentials were further investigated. When growing on different types of wastewaters, including a brewery wastewater, a livestock wastewater and a tofu wastewater, the strains produced the most carotenoid and protein with the tofu wastewater (Fig. 8 and Fig. 9). Specifically, the amount of total carotenoid produced by MD1 was fourfold higher with the tofu wastewater than with the other wastewater, while that produced by MD3 was also highest with tofu wastewater (Fig. 8). Similarly, MD1 and MD3 produced more total protein with tofu wastewater, at around $25 \mu \mathrm{g} / \mathrm{ml}$ and $35 \mu \mathrm{g} / \mathrm{ml}$ respectively 
(Fig. 9). However, for MD1, the protein production with brewery wastewater appeared to be as efficient as with tofu wastewater. The protein productions with livestock wastewater by both MD1 and MD3 were at least two-fold lower than those with other wastewater (Fig. 9).It has been reported that tofu waste includes not only starch $(6750 \mathrm{mg} / \mathrm{L})$ but also other carbohydrates such as sucrose $(800 \mathrm{mg} / \mathrm{L})$ [10]. Therefore, the higher carbohydrate content in tofu waste might be the reason for the higher carotenoid and protein production by the strains when growing with tofu wastewater.

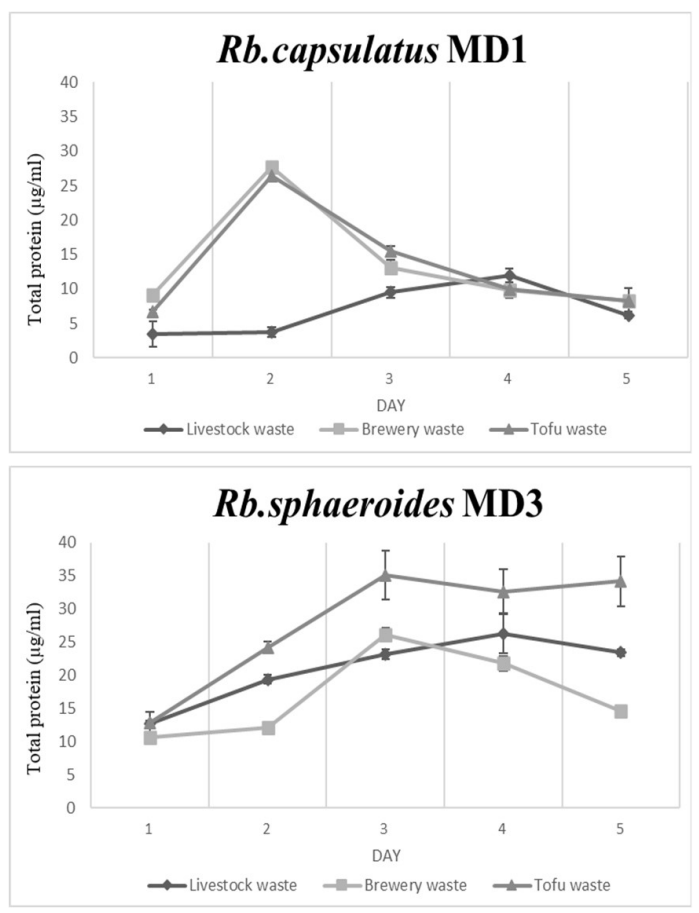

Figure 7. Protein production patterns of $R b$. capsulatus MD1 and Rb. sphaeroides MD3 when growing on various wastewater. Note: The measurements with all samples were done after 5 days of culture under same conditions (anaerobic incubation under yellow light and at temperatures around $30-35^{\circ} \mathrm{C}$ )

Furthermore, when growing with brewery wastewater, more total carotenoid was produced by $R b$. sphaeroides MD3 than by $R b$. capsulatus MD1 (Fig. 8). This result was actually reasonable and in consistent with the result of the carbon source experiment showing that maltose, a major component in brewery wastewater, was a more favored carbon source for MD3 to produce carotenoid (Fig. 3).

Altogether, our results suggest the potential of using our isolated PNSB strains as candidates for treating food processing or agriculture wastewater while at the same time converting organic waste into products with added values such as carotenoid and protein. Two strains, $R b$. capsulatus MD1 and Rb. sphaeroides MD3, are particularly promising for the conversion of waste in tofu processing to nutrients. Similar waste-to-nutrient conversion by Rhodobacter species has not been reported but these bacteria have been shown to be very efficient for treating tofu processing wastes. According to Zhu el al., $R b$. sphaeroides was applied for tofu wastewater treatment, and the TOC removal was $41 \%$ after $85 \mathrm{~h}$ [20]. Using a $R b$. sphaeroides mutant under suitable conditions, Zheng et al. showed that the average hydrogen generation from tofu wastewater could reach $14.2 \mathrm{ml} \mathrm{L}^{-1} \mathrm{~h}^{-1}$ and the COD removal efficiency was about $45 \%$ [23]. With tofu being a popular food in Vietnam, the applicability of the PNSB strains for the treatment of tofu waste and upgrade it to valuable products is very meaningful, especially for a future "green" economy. These products, which are rich in carotenoids, vitamins and protein, can be utilized for animal feed. Furthermore, tofu wastewater is a suitable medium for some PNSB species possessing hydrogenase to produce biohydrogen. The results of this study are a prerequisite for such further applications of PNSB.

\section{Conclusions}

In this study, we have applied an improved method to successfully isolate 4 PNSB strains (Rhodobacter capsulatus MD1, 


\begin{abstract}
Rhodopseudomonas palustris MD2, Rhodobacter sphaeroides MD3 and Rhodobacter sediminis MD4) from domestic wastes in Hanoi. Among the strains, Rhodobacter capsulatus MD1 and Rhodobacter sphaeroides MD3 produce higher biomass, carotenoid amounts and protein amounts when converting waste containing sugars such as glucose or maltose as the carbon source, and ammonium or urea as the nitrogen source. The two strains also demonstrated their particularly promising potentials in converting tofu processing waste to carotenoid and protein. The results of this research can be a prerequisite for further studies of using PNSB to treat food processing waste and agriculture waste and at the same time recycle nutrients and produce biomass with nutritional values.
\end{abstract}

\section{References}

[1] Thematic report on the national environment in 2017 Theme: Waste management, 2017.

[2] T. V. Nhan, N. T. Nga, Curriculum wastewater treatment technologies, Science and Technology Publishing, 1999 (in Vietnamese).

[3] T. Keskin, P. C. Hallenbeck, Hydrogen Production from Sugar Industry Wastes Using Single-stage Photofermentation. Bioresource Technology, Vol. 112, 2012, pp. 131-136.

[4] N. Mario, M. Pavlecic, B. Harutyunyan, V. Goginyan, P. Horvat, B. Santek, Characteristics and Selection of Cultures of Photosynthetic Purple Non-sulphur Bacteria as a Potential 5Aminolevulinic Acid Producers. Hrvatski časopis za prehrambenu tehnologiju, biotehnologiju i nutricionizam, Vol. 12, 2017, pp. 113-119.

[5] M.T. Madigan, D.O. Jung, An Overview of Purple Bacteria: Systematics, Physiology, and Habitats, in The Purple Phototrophic Bacteria, Springer, 2009, pp. 1-15.

[6] G. A. Sojka, Metabolism of Nonaromatic Organic Compounds. The Photosynthetic bacteria, 1978, pp. 707-718.

[7] H. Hirotani, H. Ohigashi, M. Kobayasi, E. Takahashi, Inactivation of T5 Phage by CisVaccenic Acid, an Antivirus Substance from Rhodopseudomonas Capsulata, and by Unsaturated Fatty Acids and Related Alcohols. FEMS Microbiology Letters, Vol. 77(1), 1991, pp. 13-17.
[8] R. Honda, K. Fukushi, K. Yamamoto, Optimization of Wastewater Feeding for SingleCell Protein Production in an Anaerobic Wastewater Treatment Process Utilizing Purple Non-Sulfur Bacteria in Mixed Culture Condition. Journal of Biotechnology, Vol. 125(4), 2006, pp. 565-573.

[9] J. He, G. Zhang, H. Lu, Treatment of Soybean Wastewater by a Wild Strain Rhodobacter Sphaeroides and to Produce Protein Under Natural Conditions. Frontiers of Environmental Science Engineering in China, Vol. 4, 2010, pp. 334-339.

[10] S. Ghosh, U. K. Dairkee, R. Chowdhury, P. Bhattacharya, Hydrogen from food processing wastes via photofermentation using Purple Nonsulfur Bacteria (PNSB)-A review. Energy Conversion and Management, Vol. 141, 2017, pp. 299-314.

[11] E. Sagir, E. Ozgur, I. Eroglu, U. Gunduz, M. Yucel, Single-stage Photofermentative Biohydrogen Production from Sugar Beet Molasses by Different Purple Non-sulfur Bacteria. Bioprocess and Biosystems Engineering, Vol. 40, 2017, pp. 1589-1601.

[12] R. Shapawi, T.E. Ting, S. Al-Azad, Inclusion of Purple Non-sulfur Bacterial Biomass in Formulated Feed to Promote Growth, Feed Conversion Ratio and Survival of Asian Seabass Lates Calcarifer Juveniles. Journal of Fisheries and Aquatic Science, Vol. 7(6), 2012, pp. 475-480

[13] Z. W. LaTurner, G. N. Bennett, K. Y. San, L. B. Stadler, Single Cell Protein Production from Food Waste Using Purple Non-sulfur Bacteria Shows Economically Viable Protein Products Have Higher Environmental Impacts. Journal of Cleaner Production, Vol. 276, 2020, pp. 123114

[14] R. Coico, Gram Staining. Current Protocols in Microbiology, Vol. 1, 2006, pp. A.3C.1-A.3C.2.

[15] R. C. Cooper, Photosynthetic Bacteria in Waste Treatment: Sanitary Engineering Research Laboratory \& School of Public Health. Califonia University Press, 1962.

[16] G. C. Bazire, W. R. Sistrom, R. Y. Stanier, Kinetic Studies of Pigment Synthesis by Non-sulfur Purple Bacteria. Journal of Cellular Comparative Physiology, Vol. 49, 1957, pp. 25-68.

[17] J. B. W. Hammond, N.J. Kruger, The Bradford Method for Protein Quantitation in New Protein Techniques, Springer, 1988, pp. 25-32.

[18] J. X. W. Hay, Effect of Adding Brewery Wastewater to Pulp and Paper Mill Effluent to Enhance the Photofermentation Process: Wastewater Characteristics, Biohydrogen Production, Overall Performance, and Kinetic Modeling. Environmental Science Pollution Research, Vol. 24, 2017, pp. 10354-10363. 
[19] K. Seifert, M. Waligorska, M. Laniecki, Brewery Wastewaters in Photobiological Hydrogen Generation in Presence of Rhodobacter Sphaeroides OU 001. International Journal of Hydrogen Energy, Vol. 35, No. 9, 2010, pp. 40854091.

[20] H. Zhu, Hydrogen Production from Tofu Wastewater by Rhodobacter Sphaeroides Immobilized in Agar Gels. International Journal of Hydrogen Energy, Vol. 24, 1999,pp. 305-310.

[21] L. Gabrielyan, H. Torgomyan, and A. Trchounian, Growth characteristics and Hydrogen Production by Rhodobacter Sphaeroides Using Various
Amino Acids as Nitrogen Sources and Their Combinations with Carbon Sources. International journal of hydrogen energy, Vol. 35(22), 2010, pp. 12201-12207.

[22] R. A. Herbert, E. Siefert, N. Pfennig, Nitrogen Assimilation in Rhodopseudomonas Acidophila. Archives of Microbiology Appl. Environ. Microbiol., Vol. 119, 1978, pp. 1-5.

[23] G. H. Zheng, L. Wang, Z. H. Kang, Feasibility of Biohydrogen Production from Tofu Wastewater with Glutamine Auxotrophic Mutant of Rhodobacter Sphaeroides. Renewable Energy, Vol. 35, 2010, pp. 2910-2913 